\title{
Metabolism of diglycine and triglycine by non-filtering kidneys
}

\author{
H.A.C. Sampaio ${ }^{1}$, \\ K.M. Carvalho ${ }^{2}$ \\ and M.C. Fonteles ${ }^{1}$
}

\author{
${ }^{1}$ Unidade de Pesquisas Clínicas and \\ ${ }^{2}$ Laboratório de Neurobiologia Molecular Humana, \\ Departamento de Fisiologia e Farmacologia, Faculdade de Medicina, \\ Universidade Federal do Ceará, 60436-160 Fortaleza, CE, Brasil
}

\section{Correspondence \\ M.C. Fonteles \\ Av. José Bastos, $3390 \mathrm{~s} / 90$ \\ Campus do Porangabussu \\ 60436-160 Fortaleza, CE \\ Brasil \\ Fax: 55 (085) 281-5212 \\ E-mail: upc@lia.ufc.br}

Presented at the X Annual Meeting of the Federação de Sociedades de Biologia Experimental, Serra Negra, SP, Brasil, August 23-27, 1995.

Research supported by FINEP, CNPq, CAPES and FUNCAP.

Received April 12, 1995 Accepted December 4, 1996

\begin{abstract}
We have studied the metabolism of diglycine and triglycine in the isolated non-filtering rat kidney. Kidneys from adult male Wistar Kyoto rats weighing 250-350 g were perfused with Krebs-Henseleit solution containing either $1 \mathrm{mM}$ diglycine or triglycine. The analysis of the peptide residues and their components was performed using an amino acid microanalyzer utilizing ion exchange chromatography. Diglycine was degraded to a final concentration of $0.09 \mathrm{mM}$ after 120 $\min (91 \%)$; this degradation occurred predominantly during the first hour, with a $56 \%$ reduction of the initial concentration. The metabolism of triglycine occurred similarly, with a final concentration of 0.18 $\mathrm{mM}(82 \%)$; during the first hour there was a $67 \%$ reduction of the initial concentration of the tripeptide. Both peptides produced glycine in increasing concentrations, but there was a slightly lower recovery of glycine, suggesting its utilization by the kidney as fuel. The hydrolysis of triglycine also produced diglycine, which was also hydrolyzed to glycine. The results of the present study show the existence of functional endothelial or contraluminal membrane peptidases which may be important during parenteral nutrition.
\end{abstract}

Key words

- Non-filtering kidney

- Dipeptide

- Tripeptide

- Metabolism

- Peptidases
The investigation of the handling of small peptides by the kidney is of high clinical relevance when one considers the utilization of these compounds during parenteral and enteral nutrition (1-3), since it is known that the kidney has the capacity to reabsorb and metabolize circulating peptides (4). Total parenteral nutrition could be more beneficial by replacing solutions containing single amino acids with solutions containing shortchain peptides with a high degree of stability and solubility, which can be made available by renal hydrolases for protein synthesis or the generation of energy (4). Thus, studies have been conducted on animals and hu- mans utilizing synthetic dipeptides made of cysteine, tyrosine and glutamine (5) and shortchain protein hydrolysates containing at least $67 \%$ di- and tripeptides (6). These studies showed that the use of the peptides is safe and efficient and does not cause deleterious effects $(5,6)$.

During recent years our group has been working with peptide metabolism in the kidney using the isolated rat kidney preparation as a model $(4,7)$. These studies have focused mainly on the metabolism of oligopeptides in the isolated perfused rat kidney, which exhibits both filtering and non-filtering capabilities $(4,7)$. Recently, we have investi- 
gated the metabolism of the 3 dipeptides diglycine, prolylglycine and glycylproline in the non-filtering rat kidney preparation, and we have shown variable degrees of degradation depending on the peptide used (7). In the present report, we are extending our study to the metabolism of tripeptides, beginning with triglycine.

Adult male Wistar Kyoto rats weighing 250-350 g were fasted for $24 \mathrm{~h}$ before the experiment. The animals were anesthetized with intraperitoneal sodium pentobarbital (50 $\mathrm{mg} / \mathrm{kg}$ ), and an incision in the linea alba was made and the right kidney was prepared according to Fonteles et al. (8). The ureter was then tied proximal to the kidney and perfusion was initiated.

The perfusion pressure in the system was maintained between 100 and $120 \mathrm{mmHg}$. The total volume of Krebs-Henseleit solution, $\mathrm{pH}$ 7.3-7.4, in the system was $100 \mathrm{ml}$. Di- or triglycine was added to the perfusate after an equilibration period of $25 \mathrm{~min}$ and samples were collected after 20, 40, 60, 80 and $120 \mathrm{~min}$. The samples were analyzed

Figure 1 - Metabolism of triglycine $(\bullet)$ and diglycine $(\bigcirc)$ after the infusion as a bolus of $1 \mathrm{mM}$ of each peptide in the isolated non-filtering rat kidney perfused with Krebs-Henseleit solution at $\mathrm{pH}$ 7.3-7.4. The system was kept at $37^{\circ} \mathrm{C}$ and perfusion pressure varied from $100-120 \mathrm{mmHg}$. Three experiments were done with diglycine and 8 with triglycine. Results are reported as means \pm SEM.

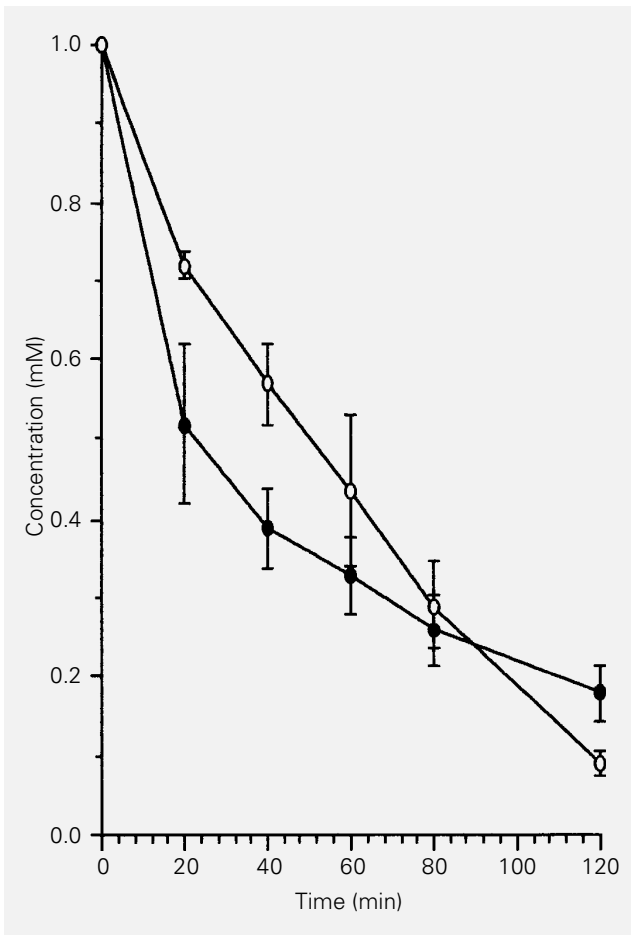

using an automated amino acid microanalyzer according to the method of Hare (9). Aliquots of 100-200 $\mu$ of the kidney perfusate were diluted with the same volume of $0.05 \mathrm{~N} \mathrm{HCl}$ and $0.2 \mathrm{M}$ sodium citrate containing $15 \%$ (w/v) polyethylene glycol and applied directly to the amino acid analyzer without further treatment. Chromatography of diglycine (Gly-Gly), triglycine (Gly-Gly-Gly) and glycine (Gly) was performed using a column packed with Aminex A-5 resin $(0.3 \times 60 \mathrm{~cm})$ equilibrated and developed at $55^{\circ} \mathrm{C}$ with $0.388 \mathrm{M}$ sodium citrate buffer, $\mathrm{pH} 3.70$ (10). The flow rate of the buffer was $10 \mathrm{ml} / \mathrm{h}$ and ninhydrin was added to the effluent at a flow rate of $5 \mathrm{ml} / \mathrm{h}$. The times of elution for Gly, Gly-Gly and Gly-Gly-Gly were 50, 90 and $102 \mathrm{~min}$, respectively. Under these conditions, the relative color yields (height/concentration) for glycine, diglycine and triglycine were $1.00,1.09$ and 0.84 , respectively. The column was standardized with $5 \mathrm{nmol}$ Gly, 10 nmol Gly-Gly and 10 nmol Gly-GlyGly.

Statistical analysis was done using the Student $t$-test for paired observations and data were processed with the Statview program in a Performa 750 MacIntosh Computer.

Diglycine disappeared almost completely after $120 \mathrm{~min}$, with only $0.09 \mathrm{mM}$ of the intact dipeptide left (Figure 1). This was expected because a previous experiment performed in our laboratory (7) showed more than $50 \%$ diglycine degradation during the first hour of perfusion. Similarly, in the present study, we observed a $56 \%$ degradation after $60 \mathrm{~min}$. Throughout the period analyzed a significant decline in diglycine concentration was observed compared to the initial period (Figure 1). Parallel to this degradation, there was the appearance of glycine in increasing concentrations up to 80 min of perfusion, with a slight decline occurring thereafter (Table 1).

Triglycine was significantly degraded (82\%) after $120 \mathrm{~min}$, with a residual concen- 


\begin{tabular}{|c|c|c|c|c|c|c|}
\hline \multirow{2}{*}{$\begin{array}{l}\text { Time } \\
\text { (min) }\end{array}$} & \multicolumn{2}{|c|}{ Gly-Gly-Gly } & \multirow{2}{*}{$\begin{array}{c}\text { Recovery } \\
\text { (\%) }\end{array}$} & \multirow{2}{*}{$\begin{array}{l}\text { Gly-Gly } \\
\text { (mM) }\end{array}$} & \multirow{2}{*}{$\begin{array}{c}\text { Recovery } \\
\text { (\%) }\end{array}$} & \multirow{2}{*}{$\begin{array}{c}\text { Glycine } \\
\text { (mM) }\end{array}$} \\
\hline & Gly-Gly (mM) & Gly (mM) & & & & \\
\hline 20 & $0.13 \pm 0.04$ & $0.54 \pm 0.19$ & $84.0 \pm 10.0$ & $0.56 \pm 0.03$ & $100.0 \pm 0.0$ & $0.94 \pm 0.09$ \\
\hline 40 & $0.17 \pm 0.05$ & $0.76 \pm 0.18$ & $82.0 \pm 9.0$ & $0.85 \pm 0.10$ & $100.0 \pm 12.0$ & $0.87 \pm 0.16$ \\
\hline 60 & $0.19 \pm 0.05$ & $1.00 \pm 0.21$ & $85.0 \pm 8.0$ & $1.20 \pm 0.22$ & $104.0 \pm 24.0$ & $0.78 \pm 0.15$ \\
\hline 80 & $0.20 \pm 0.05$ & $1.29 \pm 0.25$ & $89.0 \pm 9.0$ & $1.37 \pm 0.30$ & $98.0 \pm 25.0$ & $0.76 \pm 0.14$ \\
\hline 120 & $0.15 \pm 0.03$ & $1.66 \pm 0.39$ & $70.0 \pm 8.0$ & $1.27 \pm 0.32$ & $73.0 \pm 22.0$ & $0.69 \pm 0.17$ \\
\hline
\end{tabular}

tration of $0.18 \mathrm{mM}$ (Figure 1). As with diglycine, there was considerable hydrolysis during the first $60 \mathrm{~min}$ of perfusion, with a $67 \%$ reduction of the tripeptide. Again, throughout the observation period the values were significantly different from that of the initial period of perfusion.

The present results are relevant because there are no studies describing the metabolism of this tripeptide in the non-filtering rat kidney. Similar in vivo results were reported by Adibi and Morse (11) with intravenous administration of di-, tri- and tetraglycine to rats. These authors observed a major renal uptake of these oligopeptides, and their transformation into successively more simple constitutives, with a slight urinary excretion ( $0.2 \%$ of the infused concentration) indicating that hydrolysis probably occurred mainly in the renal tissues. On this basis we performed the present study on perfused kidney in order to determine the renal site where metabolism occurs. It is possible that the brush border membranes can also influence oligopeptide metabolism as suggested by others (12). However, our results suggest that potent degradation may be present at other kidney sites. Also in our model of isolated perfusion of the non-filtering kidneys, we observed production of diglycine and gly- cine utilizing triglycine as a substrate (Table 1). The production of glycine increased during perfusion, while the production of diglycine was relatively constant, allowing us to suggest that this peptide was continuously hydrolyzed. Similarly, during perfusion with diglycine, we observed a slight reduction in disposable glycine at the end of the period.

The recovery of diglycine and triglycine fragments at the end of each period is shown in Table 1. For both experiments, there were similar and constant values up to $80 \mathrm{~min}$, but after 120 min we observed a slight reduction in the final concentration. To determine if glycine was utilized as a fuel by the kidney, we performed experiments using this amino acid as the only substrate. The results showed a slight decline in the concentration of glycine in the first $80 \mathrm{~min}$ of perfusion and at $120 \mathrm{~min}$ the final recovery of this amino acid was about $70 \%$. These results suggest the uptake and utilization of glycine as fuel by the perfused organ. Of course, the metabolic requirements of each organ depend on many factors and the perfused kidney is a simplified model. It is possible that glycine has been partially oxidized or transformed into other products, such as serine, as demonstrated previously in our laboratory (4). 
Minami et al. (12) studied the metabolism of glycylglycylsarcosine in non-filtering rat kidney. Glycylglycylsarcosine was hydrolyzed at the Gly-Gly bond, suggesting the presence of an aminopeptidase in the peritubular compartment. Since the peptides used by these authors are different from those used in the present study, we cannot directly compare their results to ours. However, the degradation of Gly-Gly and GlyGly-Gly demonstrated in our study also suggests the presence of peptidases in the endothelium or in contraluminal membranes. Further studies on the renal metabolism of oligopeptides are needed to better understand the metabolic process of their reutil- ization after delivery to the kidney as hydrolysis by-products of larger peptides. The use of peptides rather than free amino acids during parenteral nutrition would reduce the osmolarity of the solutions and provide a higher density of calories per infused volume, as has been shown for synthetic dipeptides containing cysteine, tyrosine and glutamine (5).

\section{Acknowledgments}

The authors are indebted to Maria Silvandira Freire de França and Maria Sílvia Helena Freire de França for technical assistance.

\section{References}

1. Lochs H, Williams PE, Morse L, Abumrad NN \& Adibi SA (1988). Metabolism of dipeptides and their constituent amino acids by liver, gut, kidney, and muscle. American Journal of Physiology, 254: E588-E594.

2. Adibi SA (1989). Glycyl-dipeptides: new substrates for protein nutrition. Journal of Laboratory and Clinical Medicine, 113: 665-673.

3. Tiruppathi C, Miyamoto Y, Ganapathy V, Roesel RA, Whitford GM \& Leibach FH (1990). Hydrolysis and transport of proline-containing peptides in renal brushborder membrane vesicles from dipeptidyl peptidase IV-positive and dipeptidyl peptidase IV-negative rat strains. Journal of Biological Chemistry, 265: 1476-1483.
4. Fonteles MC, Ganapathy V, Pashley D \& Leibach FH (1983). Dipeptide metabolism in the isolated perfused rat kidney. Life Sciences, 33: 431-436.

5. Furst $P$ (1994). New parenteral substrates in clinical nutrition; new substrates in protein nutrition. European Journal of Clinical Nutrition, 48: 607-616.

6. Grimble GK, Aimer PC, Morris $P$ Raimundo A, Werik B \& Silk DBA (1992) Plasma amino acids and peptiduria during intravenous infusion of a short-chain ovalbumin hydrolysate, or its equivalent amino acid mixture in man. Proceedings of the Nutrition Society, 51: 103A.

7. Fonteles MC, Oliveira JV \& Carvalho KM (1990). Metabolism of dipeptide by isolated and perfused non-filtering rat kidney. Brazilian Journal of Medical and Biological Research, 23: 785-787.
8. Fonteles MC, Cohen JJ, Black AJ \& Weinstein S (1983). Support of kidney functions by long chain fatty acids derived from renal tissue. American Journal of Physiology, 244: F235-F246.

9. Hare PE (1977). Subnanomole-range amino acid analysis. Methods in Enzymology, 67: 3-18.

10. Duarte GIBP, Souza FGM, Bruno JA, Camargo ACM \& Carvalho KM (1988). Isolation and characterization of human brain. Neuropeptides, 12: 67-73.

11. Adibi SA \& Morse EL (1982). Enrichment of glycine pool in plasma and tissue by glycine, di-, tri- and tetraglycine. American Journal of Physiology, 243: E413-E417.

12. Minami $H$, Daniel $H$, Morse EL \& Adibi SA (1992). Oligopeptides: mechanism of renal clearance depends on molecular structure. American Journal of Physiology, 263: F109-F115. 